\title{
Prior oropharyngeal colonization and ventilator-associated pneumonia
}

\author{
Michel Rodrigues Moreira ${ }^{1}$, Joseane Cristina Ferreira ${ }^{2}$, \\ Ana Lúcia da Costa Darini ${ }^{2}$, Paulo Pinto Gontijo Filho ${ }^{1}$ \\ 1Laboratório de Microbiologia, Instituto de Ciências Biomédicas, Universidade Federal de Uberlândia, \\ Uberlândia, MG, Brazil. \\ 2Faculdade de Ciências Farmacêuticas de Ribeirão Preto, Universidade de São Paulo, \\ Ribeirão Preto, SP, Brazil.
}

Submitted: May 22, 2013; Approved: March 14, 2014.

\begin{abstract}
This study evaluated the relationship between previous colonization of the oropharynx and development of ventilator-associated pneumonia through the classification of genomic fingerprint pattern by pulsed-field gel electrophoresis of both oxacillin-resistant and oxacillin-susceptible Staphylococcus aureus isolates obtained from hospitalized patients in an intensive care unit.
\end{abstract}

Key words: oropharyngeal colonization, ventilator-associated pneumonia, Staphylococcus aureus.

The nasal carriage of $S$. aureus, including oxacillinresistant $S$. aureus (ORSA), is well known to be a significant risk factor for subsequent infection (Chen et al., 2010), mainly in primary bacteremia (von Eiff et al., 2001) and surgical site infection after major heart surgery (Muñoz et al., 2008), as well as ventilator-associated pneumonia (VAP) (Chen et al., 2010). However, some studies have shown that the throat is also an important site of staphylococcal carriage (Nilsson and Ripa, 2006; Ringberg et al., 2006; Mertz et al., 2007), and oropharyngeal colonization plays a central role in the pathogenesis of VAP (Cavalcanti et al., 2005).

This study evaluated the relationship between previous colonization of the oropharynx and development of VAP by the analysis of genomic DNA-fingerprint patterns by pulsed-field gel electrophoresis (PFGE) of both ORSA and OSSA isolates from hospitalized patients in clinicalsurgical intensive care unit (ICU) at Uberlândia Federal University Hospital Clinic (UFU-HC). UFU-HC is a teaching hospital with 500 beds and a clinical-surgical ICU for adults with 15 beds.

We conducted a longitudinal, prospective study for searching cases of oropharygeal colonization and VAP by S. aureus from May 2009 to August 2010. All patients admitted to the ICU requiring tracheal intubation and mechanical ventilation were eligible for inclusion in the study.
The cultures of the oropharyngeal secretions were taken at baseline $<24 \mathrm{~h}$ in the ICU) and every two days until the confirmation of colonization or discharge. The clinical specimen from the oropharynx was collected by swabbing the posterior pharyngeal wall. VAP criteria were: clinical, radiological and positive quantitative culture of the endotracheal aspirate (count $\geq 10^{6} \mathrm{cfu} / \mathrm{mL}$ ) (Peleg and Hooper, 2010). Only the first episode of VAP was considered for each patient. The Ethics Committee for Human Research of the Uberlândia Federal University approved this study (protocol number 364/08).

Oropharynx and endotracheal aspirate samples were cultivated in salty mannitol agar (Biobras, Belo Horizonte, MG, Brazil) by qualitative and quantitative techniques, respectively. S. aureus isolates were identified by mannitol fermentation, Gram stain, catalase, tube coagulase and clumping tests. Resistance to oxacillin was detected by means of a screening test in salty mannitol agar (Biobras) supplemented with $6 \mu \mathrm{g} / \mathrm{mL}$ of oxacillin and $4.5 \%$ of $\mathrm{NaCl}$ (CLSI, 2009), and confirmed by polymerase chain reaction (PCR) test, which was used to detect the presence of mecA gene (Pinho et al., 2001).

Isolates from both oropharynx and tracheal aspirate of patients who developed VAP were typed using PFGE, according to Kaulfmann (1998). Dendrograms were generated by using the software Bionumerics version 5.01 (Ap-

Send correspondence to M.R. Moreira. Laboratório de Microbiologia, Instituto de Ciências Biomédicas, Universidade Federal de Uberlândia, Avenida Pará 1720, Bloco 4C/36, Campus Umuarama, 38400-902 Uberlândia, MG, Brazil. E-mail: moreira.mr@hotmail.com. 
plied Maths). In addition, the band patterns were analyzed by visual comparison classified according to the criteria of Tenover et al. (1995).

In total, 617 patients were admitted to the adult ICU of the UFU-HC, and 346 (56.1\%) of them were submitted to mechanical ventilation, of which $126(36.4 \%)$ were colonized in the oropharynx with $S$. aureus $(80 / 126 ; 63.5 \%$ were ORSA and 46/126; 36.5\% were OSSA isolates).

For the total patients analyzed, VAP due to $S$. aureus was relatively low, corresponding to 11 cases (fourby ORSA and seven by OSSA), although high frequencies of colonization of the mucous membranes of the oropharynx by these microorganisms were found (ORSA 80/346; $23.1 \%$ and OSSA 46/346; 13.3\%). Among the 126 colonized patients, a total of seven (5.5\%) developed VAP: four $(5.0 \%)$ of 80 caused by ORSA and three $(6.5 \%)$ of 46 caused by ORSA.

PFGE analyses was carried out after SmaI-fragmentation of genomic DNA of 19 S. aureus isolated from 11 patients, corresponding to 11 samples of VAP and eight from colonized patients who developed VAP. In seven (63.6\%) of 11 cases of VAP an identical strain was isolated from oropharynx and endotracheal aspirate samples. Only one PFGE profile of ORSA causing VAP was observed in four patients. These samples were genetically related to those of oropharyngeal colonization of these four different patients. Two PFGE patterns were identified among our OSSA isolates, with one pattern corresponding to the isolate 19, and one major pattern subdivided into two subtypes, including the most common ones [isolates $01,05,06,07,08,09,10$ and 11] and a second corresponding to the isolate 16 (Figure 1). $100.0 \%]$

Dice $(5.0 \%-5.0 \%)(\mathrm{H}>0.0 \% \mathrm{~S}>0.0 \%)[0.0 \%-$

Seven patients had VAP caused by OSSA, three were caused by isolates of same PFGE profile [isolates 05, 07 and 09]. These isolates were similar to those of oropha- ryngeal colonization of these patients [isolates 06,08 and 10]. Three other patients had no oropharynx colonized but developed VAP by OSSA with two isolates belonging to the same clone, but different subtypes [11 and 16] and one isolate belonging to another clone [sample 19] (Figure 1). Only one patient had discordant oropharyngeal [isolate 02 - ORSA] and clinical isolates [isolate 1 - OSSA] (Figure 1).

The rate of colonization of the oropharyngeal mucosa by $S$. aureus in this study was high $(36.4 \%)$, but similar to those reported in other studies (Garrouste-Orgeas et al., 1997; Nilsson and Ripa, 2006). In the critically ill patients, the oral flora shifts dramatically to a predominance of enteric Gram-negative bacilli and $S$. aureus, upon to admission to the ICU (Safdar et al., 2005; Joseph et al., 2010). In the mechanically ventilated patient bacterial adherence is favored by reduced immunoglobulin A, augmented protease production, denuded mucous membrane, elevated airway $\mathrm{pH}$, increased numbers of airway receptor for bacteria, due to acute illness, and antibiotic use (Safdar et al., 2005; Joseph et al., 2010).

The carriage of $S$. aureus in the upper respiratory tract, mainly ORSA, is well known to be a significant risk factor for subsequent infection (Chen et al., 2010), including VAP that usually follows microaspiration of oropharyngeal secretions colonized with potentially pathogenic microorganisms (Safdar et al., 2005). In our study, among patients colonized with $S$. aureus, progression to VAP was $5.5 \%$, as opposed to only $1.8 \%$ in non-colonized ( $\mathrm{p}>0.05$ ), whereas individuals colonized by ORSA and OSSA, 5.0\% and 6.5\% developed VAP respectively, instead of $0 \%$ and $1.3 \%(p=0.003 / p=0.05)$ those not colonized by these micro-organisms, respectively.

In opposition to that observed for OSSA, PFGE analyses revealed a genomic similarity for the ORSA isolates recovered from cases of VAP and oropharyngeal colonization. In Brazil, isolates of ORSA usually correspond to the "Brazillian epidemic clone" (BEC), which belongs to the

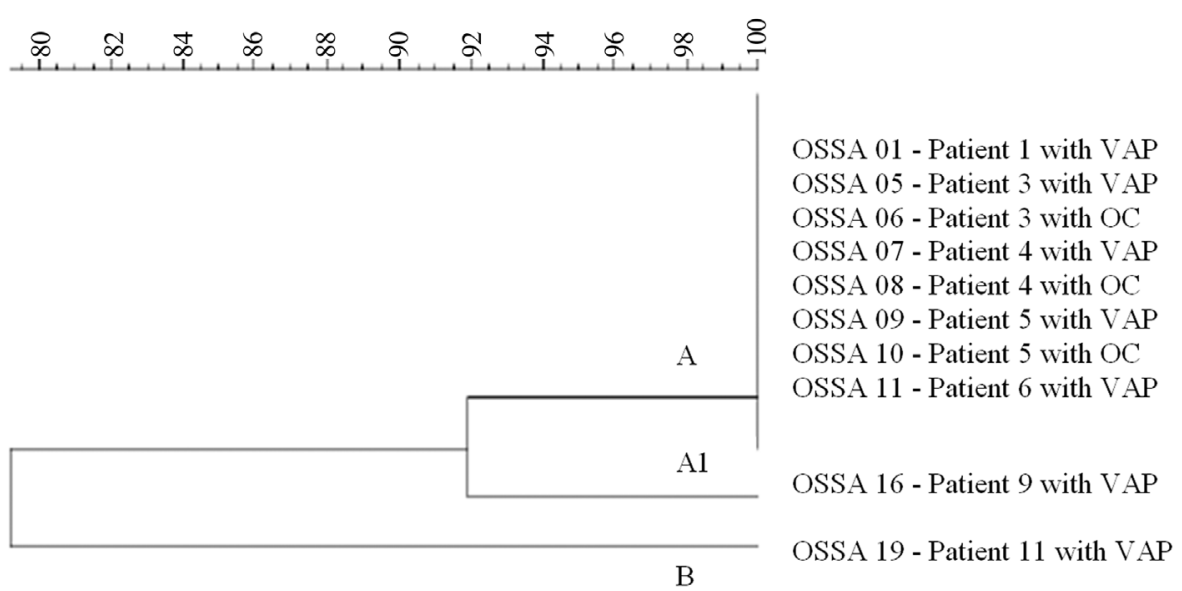

Figure 1 - Dendogram of OSSA isolates obtained from adult ICU patients at the UFU-HC. OC, oropharyngeal colonization; A, A1 and B, pulsotypes. 
type III SCCmec, and present disseminated intra-and inter-hospital in the country, so endemic in general hospitals (Coimbra et al., 2000; Soares et al., 2001; Padoveze et al., 2010). Nevertheless, we observed the presence of two OSSA clones, one represented by a single strain [19] and the other showing two subtypes with $100 \%$ and $91.5 \%$ similarity, respectively. Among patients who developed VAP by this phenotype, three were previously colonized with the same clone. Earlier, Bonten et al. (1995) reported that the oropharynx, alone or in association with the trachea was the initial site of colonization, with respectively, 13 and $14 \mathrm{mi}-$ croorganisms out of the 58 ones causing VAP.

In summary, despite the small number of isolates analyzed, the results of this study suggest an association between prior oropharyngeal colonization and VAP for $S$. aureus, with the same clones colonizing oropharynx and causing VAP.

\section{References}

Bonten MJM, Gaillard CA, van der Geest S, van Tiel FH, Beysens AJ, Smeets HG, Stobberingh EE (1995) The role of intragastric acidity and stress ulcus prophylaxis on colonization and infection in mechanically ventilated patients: A stratified, randomized, double-blind study of sucralfate $v s$. antacids. Am J Respir Crit Care Med 152:1825-1834.

Cavalcanti M, Valencia M, Torres M (2005) Respiratory nosocomial infections in the medical intensive care unit. Microbes and Infection 7:292-391.

Chen CB, Chang HC, Huang YC (2010) Nasal meticillin-resistant Staphylococcus aureus carriage among intensive care unit hospitalized adult patients in a Taiwanese medical centre: One time-point prevalence, molecular characteristics and risk factors for carriage. J Hosp Infect 74:238-244.

CLSI - Clinical and Laboratory Standards Institute (2009) Performance Standards for Antimicrobial Susceptibility Testing; Twentieth Informational Supplement. CLSI document M100-S18.

Coimbra MVS, Teixeira LA, Ramos RLB, Predari SC, Castello L, Famiglietti A, Vay C, Klan L, Figueiredo AMS (2000) Spread of the Brazilian epidemic clone of a multiresistant MRSA in two cities in Argentina. J Med Microbiol 49:187192.

Garrouste-Orgeas M, Chevret S, Arlet G, Marie O, Rouveau M, Popoff N, Schlemmer B (1997) Oropharyngeal or Gastric Colonization and Nosocomial Pneumonia in Adult Intensive Care Unit Patients. A Prospective Study Based on DNA Analysis. Am J Respir Crit Care Med 156:1647-1655.
Joseph NM, Sistla S, Dutta TK, Badhe AS, Parija SC (2010) Ventilator-associated pneumonia: A review. Eur J Intern Med 21(5):360-368.

Kaulfmann ME (1998) Pused-Field Gel Electrophoresis. In: Woodford N., Johnson A.P. (eds) Molecular Bacteriology: Protocols and Clinical Applications. Humana Press, New Jersey, pp 33-50.

Mertz D, Frei R, Jaussi B, Tietz A, Stebler C, Flückiger U, Widmer AF (2007) Throat swabs are necessary to reliably detect carriers of Staphylococcus aureus. Clin Infect Dis 45:475-477.

Muñoz P, Hortal J, Giannella M, Rodríguez-Créixems M, Pérez MJ, Rincón C, Bouza E (2008) Nasal carriage of S. aureus increases the risk of surgical site infection after major heart surgery. J Hosp Infect 68:25-31.

Nilsson P, Ripa T (2006) Staphylococcus aureus throat colonization is more frequent than colonization in the anterior nares. J Clin Microbiol 44:3334-3339.

Padoveze MC, Assis DB, Freire MP, Madalosso G, Ferreira SA, Valente MG, Fortaleza CM (2010) Surveillance Programme for Healthcare Associated Infections in the State of São Paulo, Brazil. Implementation and the first three years' results. J Hosp Infect 76:311-315.

Peleg AY, Hooper DC (2010) Hospital-Acquired Infections Due to Gram-Negative Bacteria. N Engl J Med 362(19):18041813.

Pinho MG, de Lencastre H, Tomasz A (2001) An acquired and native penicillin-binding protein cooperate in building the cell wall of drug-resistant staphylococci. Proc Natl Acad Sci USA 98:10886-10891.

Ringberg H, Petersson AC, Walder M, Johansson PHJ (2006) The throat: An important site for MRSA colonization. Scand J Infect Dis 38:888-893.

Safdar N, Crnich CJ, Maki DG (2005) The Pathogenesis of Ventilator-Associated Pneumonia: Its Relevance to Developing Effective Strategies for Prevention. Respir Care 50(6):725739.

Soares MJS, Teixeira LA, Nunes MR, Carvalho MCS, FerreiraCarvalho BT, Figueiredo AMS (2001) Analysis of different molecular methods for typing methicillin-resistant Staphylococcus aureus isolates belonging to the Brazilian Epidemic Clone. J Med Microbiol 50:732-742.

Tenover FC, Arbeit RD, Goering RV, Mickelsen PA, Murray BE, Persing DH, Swaminathan B (1995) Interpreting chromosomal DNA restriction patterns produced by pulsed-field gel electrophoresis: Criteria for bacterial strain typing. J Clin Microbiol 33:2233-2239.

von Eiff C, Becker K, Machka K, Holger S, Peters G (2001) Nasal carriage as a source of Staphylococcus aureus bacteremia. Study group. N Engl J Med 344:11-16.

All the content of the journal, except where otherwise noted, is licensed under a Creative Commons License CC BY-NC. 